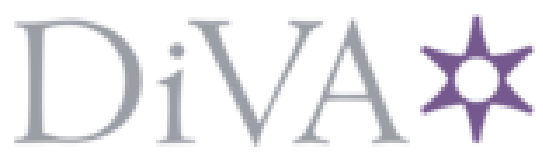

http://www.diva-portal.org

This is the published version of a paper published in .

Citation for the original published paper (version of record):

Geidne, S., Eriksson, C. (2008)

How do minors succeed in buying beer in Sweden?

Nordic Studies on Alcohol and Drugs, 25(2): 115-127

Access to the published version may require subscription.

N.B. When citing this work, cite the original published paper.

Permanent link to this version:

http://urn.kb.se/resolve?urn=urn:nbn:se:oru:diva-6845 


\section{How do minors succeed in buying beer in Sweden?}

\section{Introduction}

One of the most effective strategies for reducing problems related to alcohol is to decrease its availability (Room et al. 2005). In particular, raising the minimum age for buying alcohol has found strong support in the research. The minimum age requirements will, however, only be effective if they are properly implemented and supervised (Babor et al. 2003).

\section{Swedish alcohol policy}

In 1995 Sweden entered the European Union, whose central tenet of regulatory integration is in conflict with Sweden's restrictive alcohol policy (Holder et al. 1995; Norström \& Ramstedt 2006). A key element of this alcohol policy is to restrict the availability of alcohol, particularly to young people. In Sweden, alcoholic beverages can only be purchased at state-run stores: Systembolaget AB. The age limit is 20, with one exception; medium-strength beer (2.8-3.5\% alcohol by volume) can be purchased from the age of 18 in grocery stores. The grocery stores themselves are responsible for not selling to minors. Minors can not be punished for purchasing alcohol. The grocery

Financial support for this study was received from the Swedish National Board of Health and Welfare. The study would not have been possible to carry without the ambitious and voluntary participation of the young members of UNF.

\section{ABSTRACT}

S. Geidne \& C. Eriksson: How do minors succeed in buying beer in Sweden?

AIMS

This study examines the compliance with the law against selling beer to under-aged persons in Sweden. It also analyses determinants of compliance and the importance of checking IDs. The paper also aims to reveal the strategies used by youths when purchasing beer.

\section{METHODS \& DATA}

The study is the result of a close collaboration between the Swedish Youth Temperance Movement (UNF) and researchers at Örebro University. UNF has been responsible for the purchase attempts, and the research team for the analyses. The data consists of 681 purchase attempts in seven cities in Sweden during 2003-2004.

\section{RESULTS}

Almost half of the purchase attempts made by under-aged persons (14-17 years old) resulted in successfully buying beer. The study reveals that the genders of the check-out clerk and the buyer are significant with regard to both selling/buying beer and asking for ID. The proportion of sales was significantly higher to girls than boys, both in total and when they were asked for ID first.

\section{cONCLUSIONS}

The study shows that under-aged teenagers succeed in purchasing beer in Sweden despite the present legislation. Some succeed because of the tricks they use, and some because of the check-out clerk's negligence. The procedure used 
in the present study - letting under-aged persons attempt to purchase beer - resembles the situation for ordinary teenagers trying to buy beer under normal circumstances. $\square$ KEY WORDS

Sweden, adolescents, beer, purchase attempts, NGOs stores do not require a permit to start selling beer, but they are required to register with the municipality. The municipalities have the right to assess a fee for monitoring compliance. Failure on the part of grocery stores to obey the law can result in a warning or a sales ban (Government bill 2000/01:97).

\section{Consumption of medium-strength beer by Swedish youth}

The Swedish Council for Information on Alcohol and other Drugs (CAN) performs a yearly survey of alcohol and drug habits among Swedish schoolchildren (Hvitfeldt et al. 2004). In 2003 the survey included both sixth and ninth grade students. $25 \%$ of the boys and $15 \%$ of the girls in grade six (1213 years old) reported that they "at least once a year" drink at least one glass of beer. In grade nine (15-16 years old) 47\% of the boys and $41 \%$ of the girls made the same statement. The proportion of beer consumers in the ninth grade has decreased from around $70 \%$ at the beginning of the $1990 \mathrm{~s}$. A similar but smaller reduction was seen in grade six. In grade six, medium-strength beer is one of the most common alcoholic beverages, being the second most common among boys, and third among girls. In grade nine, medium-strength beer is the least common alcoholic beverage among girls, and among boys the next least common after wine.

\section{Purchase attempts}

During the last decade purchase attempts have been a tool in alcohol as well as tobacco research (e.g. Sundh \& Hagquist 2004; Sundh \& Hagquist 2006; Forster et al. 1994; Forster et al. 1995; Huckle et al. 2005; Schofield et al. 1994; Vaucher et al. 1995; Willner \& Rowe 2001; Willner et al. 2000; Rehnman et al. 2005; Holmila et al. 2005). In most studies the purchase attempts have been carried out by persons of legal age (to buy alcohol or tobacco), but who look younger. Two previous studies that have used minors for purchase attempts are Vaucher et al. (1995) and Willner et al. (2000). Vaucher et al. (1995) showed that alcoholic beverages were sold in $80 \%$ of the purchase attempts in bars and restaurants in Switzerland. In Willner et al. (2000), purchase attempts were made by 13 and 16-year-olds in Great Britain. The 16-year-olds were able to buy alcohol in over $80 \%$ of the attempts, and the 13-yearolds in one quarter of the attempts. Significantly higher pro- 
portions of the girls, especially of the 13year-old girls, were able to buy alcohol. A meta-analysis by the Swedish National Institute of Public Health (2004), including 30 Swedish purchase attempt studies from 1996-2004, reported no improvement over time. A majority, $60-80 \%$, were able to buy beer. A study from 2004 reported that $50 \%$ of the stores failed to ask for ID.

\section{- The Swedish Youth Temperance Movement (UNF)}

The Non-governmental organization (NGO) UNF - the Swedish Youth Temperance Movement - is a politically and religiously independent organization. It has approximately 7000 members in Sweden, all between 13 and 25 years of age. To be a member you have to be a teetotaler. UNF has a 20-year history of making purchase attempts. Their central viewpoint is that beer should not be sold in grocery stores at all, as it is more accessible to the underaged. Since UNF is an NGO, they can use minors (their own members) for the purchase attempts, although many countries, including Sweden, have legislation against entrapment methods in criminal investigations. Besides dealing with alcohol regulations and politics regarding alcohol, they also work with international exchange and democracy issues. This study is the result of a close collaboration between the Swedish Youth Temperance Movement (UNF) and researchers at Örebro University. UNF has been responsible for the purchase attempts, and the research team for the analyses.

\section{Aims}

The study has four aims. Firstly, what is the degree of compliance with the law? Can 14 to 17-year-olds buy medium-strength beer in Sweden, and are there any differences between boys and girls in different age groups with regard to their success rates at purchasing? Secondly, is it of importance for the degree of compliance where, when, and from whom the young person tries to buy the beer? Thirdly, are there any difference in who gets asked for ID, and who asks for ID? And finally, why is it that minors can sometimes buy beer even if they are asked to show ID?

\section{Methods}

Data

In the autumn of 2002 UNF received a grant from the National Board of Health and Welfare (NBHW) for the project "Folkölsprojektet" (The medium-strength beer project). One goal of the project was to build a database registering all purchase attempts. These were documented with a standardized protocol, which was made even more structured after a period of time because of the high proportion of internal missing cases in the beginning of the project. The database has been updated continuously from the spring of 2003.

In this paper, data from March 2003 to November 2004 is used. During this period, 681 purchase attempts, conducted by more than 60 buyers, in seven cities in Sweden were registered. The cities are of different sizes, the smallest having around 25000 inhabitants and the largest over a million. The database includes information on, among other things, estimated age and sex of buyers and check-out clerk, type of stores, date, time, weekday, ID, course 
of events (open-ended question) and of course whether the purchase attempt was successful or not.

\section{Purchase attempt procedure}

This project is coordinated by a national project leader and implemented by the local UNF-chapters. The local chapter, in cooperation with the national project leader, decides on the choice of different types of grocery stores and times for the purchase attempts. All the local chapters use the same procedure for purchase attempts. The basic requirements are clear:

- The buyer must be a member of UNF.

- There must be a witness over 18 years of age present at each purchase attempt.

- The buyer must agree with why UNF is performing the purchase attempts.

- The buyer must be between 14 and 17 years old.

- The buyers must behave in a realistic manner, for example, by saying that their ID is in the car when they are denied. The purchase attempts must be equivalent to reality (UNF, 2007).

Beside these requirements, UNF (2007) instruct their buyers to choose one or two buyers per store, always buy a six-pack of $3.5 \%$ beer, desirable is to buy the cheapest beer and something else as well and always use their own IDs. The buyers are instructed to act in a way that they feel comfortable with, for example be persistent or not. In the end all instructions aim to make the purchase attempt equivalent to reality. The protocol must be filled in directly after the purchase attempts. When all the chosen stores are tested the protocols, receipts and the beer must be sent to the national project leader.

\section{Analysis}

Data were converted from Microsoft Access to SPSS for windows version 13.0 and then analysed by the research team. The outcome measure of interest for the first three aims is the proportion of successful purchase attempts. In the analysis chi-square tests and 95\% confidence intervals, Mann-Whitney U-test and multivariate logistic regression have been used. The fourth aim uses the written narratives of the course of events. In this paper the qualitative content analysis was restricted to the narratives from the minors asked to show their IDs but that still could buy beer. The variation in verbal strategies will be given.

\section{Results}

\section{Compliance with the minimum age law}

Can 14-17 year-olds buy medium-strength beer in Sweden? In $43 \%$ of the 681 purchase attempts the 14-17 year-olds succeeded in buying beer. Girls performed about $70 \% \quad(n=452)$ of the purchase attempts. The proportion of sales was significantly higher among girls than boys ( $49 \%$ vs. $37 \%, \mathrm{p}=0.04$ ). The buyers who were 15 years and younger could buy beer in $42 \%$ of the attempts. The ones who were 16 years and older could buy beer in $48 \%$ of the attempts. The group with the highest proportion of minors able to buy beer was girls 16 years and older (52\% of this group could buy beer). The girls who were 15 years and younger could buy beer to a larger extent than boys who were 16 years and older ( $44 \%$ vs. $37 \%$ ). There was no significant difference between the older and the younger boys (Table 1). 
Table 1. Purchase outcome by buyer's age and sex.

\begin{tabular}{lcccc}
\hline & Attempts & Success (\%) & $95 \% \mathrm{Cl}$ & $\mathrm{p}$-value* \\
\hline All & 681 & 43 & $40-47$ & \\
Sex & & & & $\mathrm{p}=0.04$ \\
Girls & 452 & 49 & $44-54$ & \\
\hline Boys & 186 & 37 & $30-44$ & \\
Age & & & & $\mathrm{p}=0.12$ \\
$\leq 15$ & 259 & 42 & $36-48$ & \\
$\geq 16$ & 379 & 48 & $43-53$ & $\mathrm{p}=0.09$ \\
Sex and age & & & & \\
Girls $\leq 15$ & 181 & 44 & & $\mathrm{p}=0.87$ \\
$\quad \geq 16$ & 271 & 52 & & \\
\hline Boys $\leq 15$ & 78 & 36 & & \\
\hline * $\chi^{2}$-test with one df & 108 & 37 & & \\
\hline
\end{tabular}

\section{Determinants of compliance}

Is there a difference between where, when and from whom the teenagers can buy the beer? About half of the check-out clerks in this study were female. There was a tendency that female check-out clerks in this study sold beer to minors to a greater extent than male check-out clerks (51\% vs. $47 \%$, $\mathrm{p}=0.37$ ). Both male and female check-out clerks sold beer to girls to a greater extent than boys (table 2).

Table 2. Purchase outcome by check-out clerk's and buyer's gender

\begin{tabular}{lcccc}
\hline & Attempts & Success (\%) & 95\% Cl & p-value* \\
\hline Check-out assistant & & & & $\mathrm{p}=0.37$ \\
Male & 224 & 47 & $40-53$ & \\
Female & 251 & 51 & $45-57$ & \\
Missing & 206 & & & \\
\hline Male & & & $\mathrm{p}=0.15$ \\
Selling to boys & 56 & 39 & \\
Selling to girls & 165 & 50 & $\mathrm{p}=0.34$ \\
\hline Female & & & \\
Selling to boys & 61 & 46 & \\
Selling to girls & 185 & 53 & \\
\hline * $\chi^{2}$-test with one df & & & \\
\hline
\end{tabular}


Table 3. Purchase outcome by check-out clerk's age

\begin{tabular}{lcccc}
\hline & Attempts & $\begin{array}{c}\text { Success } \\
(\%)\end{array}$ & $\begin{array}{c}95 \% \\
\text { Cl }\end{array}$ & p-value* \\
\hline Check-out assistant & & & $\mathrm{p}=\mathbf{0 . 1 8}$ \\
$18-25$ & 131 & 57 & $49-66$ & \\
$25-35$ & 104 & 42 & $33-52$ & \\
$35-45$ & 52 & 56 & $42-70$ & \\
$45-55$ & 57 & 46 & $32-59$ & \\
$55-65$ & 14 & 50 & $20-80$ & \\
Missing & 323 & & & \\
\hline Check-out assistant & & & $\mathrm{p}=0.054$ \\
$<25$ & 131 & 57 & $49-66$ & \\
$>25$ & 227 & 47 & $40-53$ & \\
\hline * $\chi^{2}$-test with four and one df & & \\
\hline
\end{tabular}

There was no significant connection between the check-out clerks' estimated ages and the probability of their selling beer to minors. However, there was a tendency that those estimated to be under 25 years old sold beer to a greater extent than those estimated to be over 25 years old ( $57 \%$ vs. $47 \% \mathrm{p}=0.054$ ) (Table 3 ).

Three types of stores were tested in this study: grocery stores belonging to a national chain, petrol stations and finally other stores including kiosks and after-hours markets. Almost half of the tested stores were grocery stores. In grocery stores and other stores about $45 \%$ of the young peo- ple were able to buy beer. In petrol stations $34 \%$ were able to buy beer. The difference between petrol stations and other stores was significant $(34 \%$ vs. $46 \%, \mathrm{p}=0.031)$ (Table 4).

There was a significant difference between the seven cities included in the present analysis. The number of purchase attempts ranged from 36 attempts up to 207 per city. In the two largest cities over $50 \%$ were able to buy beer. In the smallest city, a quarter could buy beer (table 5).

Are there differences related to the time of the purchase attempt? The majority of attempts were made during 2004 (68\%). There was no difference in law compliance between 2003 and 2004; similar proportions of minors could buy beer in 2003 as in 2004. However, there was a difference due to the time of day of the purchase attempt. A higher proportion of the purchase attempts performed in the afternoon (12 pm to $6 \mathrm{pm}$ ) resulted in a purchase of beer ( $58 \%$ vs. 42 or $43 \%$ evening and morning, $\mathrm{p}=0.003$ ). There was also a difference in what day of the week the purchase attempts occurred. Most of the purchase attempts were conducted on Fridays and Saturdays and those were also the days with the highest proportion of succeeded purchase attempts (Table 6).

Table 4. Purchase outcome by store

\begin{tabular}{|c|c|c|c|c|}
\hline & Attempts & Success (\%) & $95 \% \mathrm{Cl}$ & $p$-value* \\
\hline Store & & & & $p=0.09$ \\
\hline Petrol station & 114 & 34 & & \\
\hline Grocery store & 305 & 44 & & \\
\hline $\begin{array}{l}\text { Other stores (e.g. kiosks, } \\
\text { after-hours markets) }\end{array}$ & 262 & 46 & & $p=0.03^{\star \star}$ \\
\hline
\end{tabular}


Table 5. Purchase outcome by city

\begin{tabular}{lcccc}
\hline & Attempts & Success (\%) & $95 \% \mathrm{Cl}$ & $\mathrm{p}$-value \\
\hline \multicolumn{2}{l}{ City (descending population) } & & & $\mathrm{p}<0.001$ \\
Stockholm & 207 & 52 & $45-59$ & \\
Gothenburg & 65 & 57 & $45-69$ & \\
Norrköping & 36 & 42 & $25-59$ & \\
Umeå & 94 & 49 & $39-59$ & \\
Karlstad & 72 & 46 & $34-58$ & \\
Motala & 139 & 30 & $22-37$ & \\
Söderhamn & 68 & 24 & $13-34$ & \\
\hline${ }^{*} \chi^{2}$-test with six df & & & &
\end{tabular}

In addition to these results a multivariate logistic regression has been performed to analyse more than one variable at a time. The result indicates that it is over three times (OR=3.1; CI 1.7-5.7) more likely that buyers 16 years and older can buy beer compared to the younger ones. That purchase attempts in all cities except Karlstad is more likely to be successful than in Söderhamn (the smallest city). Contrary to the result above it also indicates that it is almost three times (OR=2.8; CI 1.2-6.4) more likely that a purchase attempt ended up successful in 2003 than 2004.

Table 6. Purchase outcome by year, time of day

\begin{tabular}{lcccc}
\hline & Attempts & Success (\%) & $95 \% \mathrm{Cl}$ & $\mathrm{p}$-value* \\
\hline Year & 219 & 44 & $\mathrm{p}=0.85$ \\
2003 & 462 & 43 & \\
2004 & & & $\mathrm{p}<0.001$ \\
\hline Weekday & 74 & 43 & \\
Monday & 19 & 37 & \\
Tuesday & 109 & 29 & \\
Wednesday & 56 & 21 & \\
Thursday & 167 & 47 & \\
Friday & 248 & 52 & \\
Saturday & 8 & 75 & \\
Sunday & & & \\
\hline Time & 60 & 43 & \\
\hline Before 12 pm & 147 & 58 & \\
12 pm - 6 pm & 357 & 42 & \\
After 6 pm & & & \\
\hline * $\chi^{2}$-test with one and two df & & \\
& & & \\
\hline
\end{tabular}


Table 7. Purchase outcome when ID is requested, according to buyer

\begin{tabular}{lcccc}
\hline & Attempts & Asked (\%) & Success (\%) & $\mathrm{p}$-value* \\
\hline All & & & & $\mathrm{p}<0.001$ \\
Asked for ID & 416 & 100 & 15 & \\
Not asked for ID & 215 & 0 & 100 & \\
\hline Sex & & & & $\mathrm{p}=0.197^{\star \star}$ \\
Boys & 182 & 70 & 7 & \\
Girls & 438 & 64 & 19 & $\mathrm{p}=0.002^{\text {***}}$ \\
\hline Age & & & & $\mathrm{p}=0.20^{\text {** }}$ \\
$\leq$ & 254 & 69 & 14 & \\
$\geq$ & 366 & 64 & 17 & $\mathrm{p}=0.413^{\star \star \star}$ \\
\hline
\end{tabular}

${ }^{*}{ }^{2}$-test with one df ${ }^{* *}$ asked ${ }^{\star * \star}$ succeeded

\section{Importance of checking ID}

Is there any difference in who gets asked for ID and who asks for ID? One third of the participants could buy beer without anyone asking them for ID. The other two thirds were asked for ID, but $15 \%$ of those could still buy beer. There was no significant difference between the proportions of girls or boys who were asked for their IDs. Nevertheless girls were able to buy beer to a greater extent than boys $(19 \%$ vs. $7 \%$, $\mathrm{p}=0.002)$.
There was no significant difference between the younger and the older teens when it comes to being asked for ID and still being able to buy beer (Table 7).

The sex of the check-out clerk had no impact on asking for ID. There was, however, a significant difference in selling beer despite having asked for ID. Female checkout clerks sold beer without checking to a greater extent $(24 \%$ vs. $13 \%, p=0.014)$. Older check-out clerks asked for ID to a greater extent than younger ones $(68 \%$ vs.

Table 8. Purchase outcome when ID is requested, according to check-out clerk

\begin{tabular}{lcccc}
\hline & Attempts & Asked (\%) & Success (\%) & $\mathrm{p}$-value* \\
\hline Gender & & & & $\mathrm{p}=0.608^{\star *}$ \\
Male & 213 & 62 & 13 & \\
Female & 244 & 65 & 24 & $\mathrm{p}=0.014^{\star \star \star}$ \\
\hline Age & & & $\mathrm{p}<0.001^{* *}$ \\
$<25$ & 125 & 49 & 10 & \\
$>25$ & 218 & 68 & 20 & $\mathrm{p}=0.09^{\star \star \star}$ \\
\hline${ }^{*} \chi^{2}$-test with one df ${ }^{* *}$ asked ${ }^{* * *}$ succeeded &
\end{tabular}


Table 9. Purchase outcome when ID is requested, by store

\begin{tabular}{|c|c|c|c|c|}
\hline & Attempts & Asked (\%) & Success (\%) & p-value* \\
\hline Store & & & & $\mathrm{p}=0.012^{\star \star}$ \\
\hline Petrol station & 112 & 76 & 13 & \\
\hline Grocery stores & 295 & 67 & 17 & \\
\hline $\begin{array}{l}\text { Other stores (e.g. } \\
\text { kiosks, after-hours } \\
\text { markets) }\end{array}$ & 224 & 60 & 13 & $\mathrm{p}=0.519^{\star \star \star}$ \\
\hline
\end{tabular}

$49 \%, \mathrm{p}<0.001)$ despite the fact that older check-out clerks tended to sell beer to a greater extent ( $20 \%$ vs. $10 \%, \mathrm{p}=0.086$ ) (Table 8).

There was a difference between the proportions who were asked for ID between the different stores. In $76 \%$ of the purchase attempts made at petrol stations, the minor was asked for ID. This was the highest proportion of all the types of stores. In grocery stores, $67 \%$ were asked for ID, and in other stores $60 \%$ (Table 9).

\section{- Youth Strategies for Purchasing}

Why is it that under-aged persons sometimes can buy beer even if they are asked to show ID?

In three quarters of the purchase attempts the buyer wrote down the course of events. The descriptions are written in a potted version with quite a few slang expressions. In spite of this they reveal a great deal about the meetings between the teenagers and check-out clerks. The ones chosen for this particular study are the comments occurring when the minor has been asked for ID, but still could buy beer ( $n=63$ ). Of these 63 comments, 16 were not interpretable. The remaining 47 can be divided into two groups both of which could buy beer, the ones who showed their
ID and the ones who did not.

Starting with the ones who did not show their IDs, many different tricks were used. Some examples are:

"Went in, took the beer, was going to pay when the check-out clerk asked for ID. I showed her the car keys and said that my driver's license was at home."

“Took a six-pack. The check-out clerk asked for ID. I told him it hasn’t arrived yet. He mumbled 'I don't give a shit' and registered the beer."

"The woman at the check-out asked for ID. I said that it was at home. The check-out clerk explained that everyone under 40 was asked for ID, but it was OK this time."

"The buyer went in to the store, got a six-pack of beer, went to the check-out where the check-out clerk asks for ID. The buyer answers that she forgot it, but that she usually buys beer in this store. The check-out assistant said OK and sold the beer."

The ones connected to cars and drivers licenses are among the most common, be- 
cause the age limit for driving cars is 18 years in Sweden. What are the responses to these tricks then? Some of the check-out clerks believe the explanations straight away, while others are more hesitant. In some cases the teens have to persuade the check-out clerk, but often it is not a long discussion.

Even more peculiar are the cases where they actually showed their ID, but could still buy beer.

Some examples are:

"Went in and took the beer, picked some sweets, went to the check-out. The check-out clerk asked for ID. She looked at the ID, but much too fast, hadn't a chance to see what year it said."

"Got asked for ID immediately. ID was shown. Question: 'but you are not 18, are you' The buyer: Yes, I am Clerk: Okay, then."

"Brought the beer, she asked for ID, but she didn't know how old you are if you were born in 87. I told her that you are 18."

"Went in, took the beer, he asked for ID, I showed him, he said 'well 85', it said 88. I paid and went out."

It seems that many of the check-out clerks did not look at the IDs thoroughly enough. Some of them even appear to sell to minors deliberately.

\section{Discussion}

This study is the result of a close collaboration between the Swedish Youth Tem- perance Movement (UNF) and a research team at the University of Örebro. According to Green (2001) these types of studies where the gap between university-centred research and, for example, local groups, is bridged - are needed to ensure that future research is relevant to local needs.

In this study UNF has been responsible for the purchase attempts and the research team for the analysis, though cooperation has occurred during the process.

An important precondition for this research collaboration is the high quality of the UNF's systematic way of conducting purchase attempts. Although this strategy could mean less control on the side of the researchers, this is outweighed by the benefits of an NGO conducting the purchase attempts. As an NGO they can sometimes use radical and new methods. In this case that means, among other things, that they can use under-aged persons for their purchase attempts, to make them as realistic as possible.

It is no surprise that almost half of the purchase attempts in the present study resulted in the buying of beer. Many previous studies from Sweden (Swedish National Institute of Public Health 2004) as well as other part of the world (Holmila et al. 2005) show similar or even worse results. In this study girls could buy beer to a greater extent than boys. That is also the case in Forster et al. (1995) and Willner et al. (2000), but not in the case of purchasing tobacco in Sundh \& Hagquist (2006) where the tendency was the opposite. There is also the question of who is selling the beer. Sundh \& Hagquist (2006) find no correlation with check-out clerks' sex and age. Forster et al. (1994) finds a difference connected with age. In the present study, 
we find a tendency towards a difference based on gender and age. Female checkout clerks sell to minors to a greater extent than males, and check-out clerks below the age of 25 sell to a greater extent. The fact that female check-out clerks sell more frequently than males could be because they were a bit younger than the males. It could also be explained by the fact that females, according to Willner \& Rowe (2001) make higher age estimates than males do. The result may be skewed by the fact that the proportion of missing cases was quite high. It is especially interesting to compare the check-out clerk's gender with that of the buyer, because both male and female check-out clerks sell beer to girls to a greater extent than boys. An interesting fact is that the type of store doesn't seem to matter, something at least the stores in the national chains believed.

Only a third of the participants in this study were not asked for ID when they tried to buy beer. This is quite low compared to Forster et al. (1995), who say that a majority of young people in their study could purchase alcohol without showing ID, and also to Swedish conditions where Sundh \& Hagquist (2006) claim that two thirds of the minors were not asked for ID when they tried to buy cigarettes. This could be due to the fact that in this study the participating young people actually were under-aged. An interesting result is the $15 \%$ who could buy beer despite their being asked for ID. In Sundh \& Hagquist (2006) 9\% could buy cigarettes despite being asked for ID. In their study, however, none of the buyers had their ID with them. In our study the teenagers have in some cases actually presented their own IDs and still succeeded with the purchase attempt. Willner \& Rowe (2001) conclude that around half of all sales of alcohol to underage persons can be connected to misperceptions of age, but that other factors must account for the other half. This is very obvious in this study in some of the instances when participants have actually shown their own IDs. Willner et al. (2000) assert that sales were less likely to occur when there was more than one vendor present; this would suggest that some vendors knew that the buyers were underage. Reading some of the course of events narrated in this study inclines one to believe that selling to minors can sometimes be intentional. But why?

NBHW's decision to provide funding to UNF was questioned, since purchase attempts made by minors could be seen as entrapment. Lawyers at NBHW investigated the issue and decided that it was okay to provide funding as long as UNF financed the purchases of beer themselves. The youth in UNF are, as members, doing this totally voluntarily, and there is always a witness over 18 years of age present outside the store. To do this kind of practicebased research you have to let the practitioners be the owners of the project. We have confidence in their handling of their actions and have been a part of their process during the project. These procedure challenges us to also consider ethical principles basic to research. Issues of maintaining confidentiality, weighing the risk and benefits of a study and paying attention to promoting justice and equality are important. The researchers in this study have in the analysis of the database in no way violated these basic principles.

This study has shown, as other studies have shown, that it is quite easy for minors 
to buy beer in grocery stores in Sweden. It has also shown that the genders of the check-out clerk and of the buyer are significant. The study has given a picture of how teens in Sweden manage to purchase beer and the tricks they use. These tricks are probably used by ordinary teenagers as well.

Future research will tell which of the following methods gives the best results if you want to improve the practice of grocery stores: a method based on cooperation with the stores, or a method based on confronting the stores.

\section{REFERENCES}

Babor, T. \& Caetano, R. \& Casswell, S. \& Edwards, G. \& Giesbrecht, N. \& Graham, K. \& Grube, J. \& Gruenewald, P. \& Hill, L. \& Holder, H. \& Homel, R. \& Österberg, E. \& Rehm, J. \& Room, R. \& Rossow, I. (2003): Alcohol: no ordinary commodity- research and public policy. Oxford: Oxford University Press

Forster, J. \& McGovern, P. \& Wagenaar, AC. \& Wolfson, M. \& Perry, C. \& Anstine, P. (1994): The ability of young people to purchase alcohol without age identification in north eastern Minnesota, USA. Addiction 89: 699-705

Forster, J. \& Murray, D. \& Wolfson, M. \& Wagenaar, AC. (1995): Commercial Availability of Alcohol to Young People: Results of Alcohol Purchase Attempts. Preventive Medicine 24: 342-347

Government bill 2000/01:97. Vissa ändringar $i$ alkohollagen [Some changes in the Swedish alcohol law]

Green, L W. (2001): From Research to "Best Practices" in Other Settings and Populations. American Journal of Health Behaviour 25 (3): 165-178

Holder, H. \& Giesbrecht, N. \& Horverak, Ø. \& Nordlund, S. \& Norström, T. \& Olsson, O. \& Österberg, E. \& Skog, O. (1995): Potential consequences from possible changes to
Susanna Geidne, PhD Student Public Health

Sciences,

School of Health and Medical Sciences,

Örebro University,

S-70182 Örebro,

Sweden

E-mail: susanna.geidne@hi.oru.se

Charli Eriksson, professor,

School of Health and Medical Sciences,

Örebro University,

S-70182 Örebro,

Sweden

E-mail: charli.eriksson@hi.oru.se

Nordic retail alcohol monopolies resulting from European Union membership. Addiction 90: 1603-1618

Holmila, M. \& Karlsson, T. \& Raitasalo, K. (2005): Minderårigas alkoholköp. [Buying of alcohol by minors]. Nordic Studies on Alcohol and Drugs 22 (5): 350-357.

Huckle, T. \& Conway, K. \& Casswell, S. \& Pledger, M. (2005): Evaluation of a regional community action intervention in New Zealand to improve age checks for young people purchasing alcohol. Health Promotion International 20: 147-155

Hvitfeldt, T. \& Andersson, B. \& Hibell, B.(2004): Skolelevers drogvanor 2003. [Drug abuse among students 2003]. Stockholm: The Swedish Council for Information on Alcohol and other Drugs (CAN), Report No. 77, 2004.

Norström, T. \& Ramstedt, M. (2006): Sweden - is alcohol becoming an ordinary commodity? Addiction 101: 1543-1545

Rehnman, C. \& Larsson, J. \& Andréasson, S. (2005): The beer campaign in Stockholm - Attempting to restrict the availability of alcohol to young people. Alcohol 37: 65-71

Room, R. \& Babor, T. \& Rehm, J. (2005): Alcohol and public health. Lancet 365: 519-530 Schofield, MJ. Weeks, C. Sanson-Fisher, R. (1994): Alcohol Sales to Minors: A surroga- 
te Study. Preventive Medicine 23: 827-831

Sundh, M. \& Hagquist, C. (2004): The importance of a minimum age law for the possibility of purchase of tobacco by adolescents: a study based on Swedish experiences. Scandinavian Journal of Public Health 32: 68-74

Sundh, M. \& Hagquist, C. (2006): Compliance with a minimum-age law of 18 for the purchase of tobacco - the case of Sweden. Health Education Research 21 (3): 378-385

Swedish National Institute of Public Health (2004): Folköl och ungdomar. [Mediumstrength beer and youth].

UNF. The Swedish Youth Temperance Movement. [http://folkol.unf.se]. 2007-10-22
Vaucher, S. \& Rehm, J. \& Benvenuti, J. \& Müller, R. (1995): Young teenagers and access to alcohol in a Swiss canton: evidence from observational testing and from a telephone survey. Addiction 90: 1619-1625

Willner, P. \& Hart, K. \& Binmore, J. \& Cavendish, M. \& Dunphy, E. (2000): Alcohol sales to underage adolescents: an unobtrusive observational field study and evaluation of a police intervention. Addiction 95(9): 1373-1388

Willner, P. \& Rowe, G. (2001): Alcohol Servers' Estimates of Young People’s Ages. Drugs: education, prevention and policy 8: 375-383. 